\title{
Membrana amniótica canina utilizada como bandagem em úlcera superficial de córnea de coelhos - aspectos clínicos
}

[Canine amniotic membrane used as a bandage on rabbit superficial corneal ulceration-clinical aspects]

\author{
K.C.S. Pontes ${ }^{1}$, A.P.B. Borges ${ }^{2}$, T.S. Duarte ${ }^{3}$, G.L. Morato ${ }^{4}$, V. Zavan $^{4}$, \\ R.B. Eleotério ${ }^{4}$, E.C. Carlo ${ }^{1}$ \\ ${ }^{1}$ Aluna de pós-graduação - UFV - Viçosa, MG \\ ${ }^{2}$ Universidade Federal de Viçosa \\ Av. PH Rolfs, $\mathrm{s} / \mathrm{n}$ \\ 36570-000 - Viçosa, MG \\ ${ }^{3}$ Médica veterinária autônoma \\ ${ }^{4}$ Aluno de graduação - UFV - Viçosa, MG
}

\begin{abstract}
RESUMO
Realizou-se a ceratectomia superficial em 28 coelhos, distribuídos em dois grupos. No grupo tratado, composto por 14 animais, utilizou-se a membrana amniótica canina como bandagem, suturada com sua face epitelial voltada contra a superfície corneana. $\mathrm{O}$ grupo controle não recebeu tratamento. A avaliação clínica foi realizada 24 horas após a cirurgia, a cada dois dias durante uma semana e a cada quatro dias até 180 dias. Avaliaram-se os efeitos da membrana amniótica como bandagem, comparando-se o tempo de epitelização da córnea entre os grupos e verificando o período necessário para que a córnea apresentasse transparência completa. A opacidade corneana esteve presente em todos os animais durante o período observado. O tratamento instituído resultou clinicamente em neovascularização corneana, opacidade de córnea mais intensa no período inicial de reparação, retardou o processo de epitelização e causou mais dor e desconforto que nos animais do grupo-controle.
\end{abstract}

Palavras-chave: coelho, córnea, membrana amniótica, ceratite ulcerativa

\begin{abstract}
Twenty-eight rabbits were submitted to superficial keratectomy. The treated group consisted of 14 animals received canine amniotic membrane as a bandage, sutured in a way that its epithelial surface was in contact with the corneal surface. The control group did not receive any treatment. The animals were submitted to clinical evaluations 24 hours after surgery, at each two-day interval during one week and at each four-day interval during 180 days. The amniotic membranes were evaluated as a bandage comparing the time needed for corneal epithelization in the treated and non-treated groups and determining the period necessary for the cornea to become completely transparent. The corneal opacity was present during the entire time of observation. The treated animals presented more opaque cornea in the early period of regeneration, with neovascularization and more pain and discomfort than the animals from control group, showing a delayed epithelization.
\end{abstract}

Keywords: rabbit, cornea, amniotic membrane, ulcerative keratitis

\section{INTRODUÇÃO}

As úlceras de córnea, ou ceratite ulcerativa, são uma das doenças oculares mais comuns em cães e gatos. Nos casos de ceratite ulcerativa grave, pode ocorrer a perda do globo ocular devido a complicações como endoftalmites, glaucoma ou phthisis bulbi. No entanto, as ceratites ulcerativas

Recebido em 27 de dezembro de 2006

Aceito em 29 de agosto de 2008

E-mail: kellycpontes@yahoo.com.br 
são as doenças oculares que melhor respondem ao tratamento entre todas as doenças oftálmicas tratáveis (Whitley, 1991). Podem se complicar quando o mecanismo de reparação normal é inibido ou desequilibrado, quando a causa que resultou na ulceração não foi eliminada ou quando a lesão foi contaminada por agentes infecciosos. Se o equilíbrio entre a regeneração e a destruição no processo de reparação não existir, desenvolve-se uma destruição progressiva do estroma (Kern, 1990).

As ceratites ulcerativas persistentes, não responsivas ao tratamento clínico, requerem a terapia cirúrgica para a sua reparação (Portnoy et al., 1989). Os objetivos deste tipo de terapia são reparar a úlcera e prevenir a sua progressão, proteger a superfície da córnea durante a fase de reparação e retardar a degeneração do estoma.

Muitos tipos de membranas biológicas têm sido estudadas em cirurgias oftálmicas reconstrutivas na medicina humana e veterinária. São utilizados implantes de membranas autógenos, alógenos e xenógenos na tentativa de reconstruir superfícies oculares após traumas ou excisões cirúrgicas, obtendo-se resultados considerados satisfatórios. Dentre os diversos tipos de membranas biológicas, o uso da membrana amniótica tem demonstrado bons resultados em cirurgias oculares (Woo et al., 2001; Dua et al., 2004; Barros et al., 2005; Cremonini et al., 2007).

A ultra-estrutura do epitélio da membrana amniótica tem muitas funções especializadas, entre elas destacam-se: efeito antiadesivo, propriedades bacteriostáticas, proteção da lesão, redução da dor, efeito na epitelização, e ausência de imunogenicidade (Trelford e Trelford-Sauder, 1979; Azuara-Blanco et al., 1999; Sampaio et al., 2006).

A utilização da membrana amniótica em cirurgias oftálmicas pode se dar de duas formas. Como enxerto, quando a membrana é usada como um substrato para a migração celular, tornando-se epitelizada e incorporada ao tecido receptor, devendo ser posicionada com sua face epitelial voltada para cima e como bandagem, primariamente para conter a reação inflamatória enquanto a epitelização está ocorrendo sob ela. Nesse caso, a membrana deverá ser posicionada com a sua face epitelial contra a superfície ocular (Dua et al., 2004).
Neste experimento, a membrana amniótica foi utilizada como bandagem, sendo suturada com a sua face epitelial posicionada contra a córnea lesada após a realização de ceratectomia superficial. Os objetivos desta pesquisa foram: a) estudar os efeitos clínicos da membrana amniótica canina, utilizada como bandagem, no tratamento de úlceras de córnea superficiais; b) avaliar clinicamente o tempo necessário para ocorrer a transparência completa da córnea, após o processo de reparação nos dois grupos; c) comparar, clinicamente, o tempo de epitelização corneana entre os grupos.

\section{MATERIAL E MÉTODOS}

Este estudo seguiu as normas para experimentação oftalmológica seguindo os critérios da Association for Research in Vision and Ophthalmology (ARVO), no qual apenas um dos olhos de cada animal foi comprometido ${ }^{1}$. Assim, as alterações relacionadas ao ato cirúrgico e ao processo de reparação corneana produziram mínima interferência com o bemestar do animal, durante o período pósoperatório.

As membranas utilizadas foram coletadas, de forma asséptica, de uma cadela gestante com fetos a termo. As membranas amnióticas foram separadas do córion, imersas em solução tampão fosfato $^{2}$ estéril, contendo $1000 \mathrm{UI} / \mathrm{ml}$ de penicilina $\mathrm{G}, 20 \mathrm{mcg} / \mathrm{ml}$ de estreptomicina e $2,5 \mathrm{mcg} / \mathrm{ml}$ de anfotericina $\mathrm{B}^{1}$, estendidas sobre papel de nitrocelulose, com sua face epitelial voltada para cima, cortadas no tamanho de $3 \mathrm{~cm}^{2}$; imersas em frascos individuais, contendo glicerina a $99 \%$ e estocadas em temperatura ambiente, por um período mínimo de 30 dias antes da avaliação microbiológica.

Foram utilizados 28 coelhos da raça Nova Zelândia, adultos, hígidos, com pesos entre $3 \mathrm{~kg}$ e $4 \mathrm{~kg}$, separados aleatoriamente em dois grupos eqüitativos, sendo um tratado, que recebeu a bandagem com a utilização de membrana amniótica xenógena, e um grupo-controle, sem tratamento.

\footnotetext{
${ }^{1}$ Aprovado pela Comissão de Ética da Universidade Federal de Viçosa - protocolo n ${ }^{\circ}$ 85/2006.

${ }^{2}$ Ophthalmos Fórmulas Oficinais Ltda. - São Paulo, SP.
} 
Após os procedimentos pré-cirúrgicos e anestésicos de rotina, em todos os animais realizou-se a ceratectomia superficial no olho esquerdo, com auxílio de um trépano de Castroviejo $^{3}$, a $3 \mathrm{~mm}$ do limbo na posição 2 horas, retirando-se um fragmento corneano de $5,0 \mathrm{~mm}$ de diâmetro e $0,15 \mathrm{~mm}$ de espessura.

No grupo tratado, um fragmento da membrana amniótica, previamente hidratado por 10 minutos, foi posicionado no defeito corneano com sua face epitelial voltada contra a córnea. A membrana foi fixada à córnea por meio de sutura com pontos simples separados ao redor do defeito corneano, utilizando-se fio de nylon 9-0 $0^{4}$. A sutura deixou as bordas do defeito livre e atravessou totalmente o implante, mas não totalmente a córnea receptora.

No tratamento pós-operatório, foi feita a aplicação de colírio à base de neomicina, polimixina $\mathrm{B}$ e bacitracina ${ }^{1} \mathrm{e}$ de colírio à base de atropina $^{1}$, na dose de uma gota a cada quatro horas, por 15 dias. Todos os animais foram mantidos em baias individuais e utilizaram colar do tipo elizabetano até a completa epitelização da lesão corneana.

A remoção da sutura, dos animais do grupo tratado, foi feita após o início da queda do implante, com os animais submetidos à sedação, seguida pelo uso de colírio anestésico.

O exame clínico constou de oftalmoscopia direta para a avaliação de blefarospasmo, secreção ocular, congestão de vasos conjuntivais, neovascularização corneana e permanência do implante e presença de prurido. Tais parâmetros foram considerados como presentes ou ausentes. Foi feito o teste de fluoresceína para verificar a presença da membrana no grupo tratado e o grau de epitelização da área que sofreu a ceratectomia no grupo-controle e no grupo tratado após a remoção do implante.

Todos os parâmetros foram verificados 24 horas após a cirurgia, a cada 48 horas durante os primeiros sete dias de pós-cirúrgico e, a cada quatro dias, até o final do período de observação de cada grupo.

${ }^{3}$ Petrovich Instrumentos Cirúrgicos - São Paulo, SP

${ }^{4}$ NP6590 Oftalmologia/ PolySuture Ind. e Com. Ltda. - São Sebastião do Paraíso, MG.
A opacidade da córnea e do implante foi classificada como ausente, quando um ou outro se apresentaram completamente transparentes, discreta, quando se apresentaram com coloração branca, mas ainda permitindo a visualização da câmara anterior e intensa, quando se apresentaram com coloração branca, sem permitir a visualização da câmara anterior.

O teste estatístico utilizado foi o não-paramétrico de Wilcoxon, considerando o nível de significância $\mathrm{P}<0,05$.

\section{RESULTADOS E DISCUSSÃO}

O blefarospasmo foi significativamente maior até o nono dia de pós-operatório nos animais do grupo tratado. A partir do décimo dia, não houve diferença entre os grupos (Tab. 1). Acredita-se que o atrito do fio de sutura com a conjuntiva palpebral pode ter causado o blefarospasmo (Barros et al., 1998), e que uma possível formação de tecido de granulação sepultando o fio pode ter levado à sua resolução espontânea (Garcia et al., 1996).

A secreção ocular foi estatisticamente mais acentuada nos animais do grupo tratado até o $12^{\circ}$ dia de pós-operatório; a partir do $13^{\circ}$ dia, não se observou diferença entre os grupos (Tab. 2). A variável congestão dos vasos conjuntivais também se mostrou mais significante nos animais do grupo tratado até o $15^{\circ}$ dia de pósoperatório (Tab. 3). Como descrito por AzuaraBlanco et al. (1999), a membrana amniótica apresenta propriedades bacteriostáticas e não possui imunogenicidade. Além disso, foi identificada a presença de inibidores inflamatórios nas células epiteliais da membrana amniótica (Hao et al., 2000) e a ausência de leucócitos no âmnio, permitindo a prática do halo-transplante por não induzir à rejeição (Trelford e Trelford-Sauder, 1979). Dessa forma, esses sinais sugerem a possível ocorrência de reação inflamatória ao fio de sutura e não à presença da membrana amniótica atuando como corpo estranho no local. 
Tabela 1. Valores médios obtidos relacionados ao blefarospasmo em coelhos dos grupos tratado (T) e controle $(\mathrm{C})$ após o procedimento cirúrgico

\begin{tabular}{lrrrrrrrr}
\hline \multirow{2}{*}{ Grupo } & \multicolumn{7}{c}{ Dia de observação } \\
\cline { 2 - 9 } & 1 & 2 & 3 & 7 & 8 & 9 & 10 & 14 \\
\hline $\mathrm{T}$ & $1,00 \mathrm{a}$ & $1,14 \mathrm{a}$ & $1,28 \mathrm{a}$ & $1,64 \mathrm{a}$ & $1,71 \mathrm{a}$ & $1,78 \mathrm{a}$ & $1,86 \mathrm{a}$ & $1,93 \mathrm{a}$ \\
$\mathrm{C}$ & $1,79 \mathrm{~b}$ & $1,78 \mathrm{~b}$ & $2,00 \mathrm{~b}$ & $2,00 \mathrm{~b}$ & $2,00 \mathrm{~b}$ & $2,00 \mathrm{~b}$ & $2,00 \mathrm{a}$ & $2,00 \mathrm{a}$ \\
\hline
\end{tabular}

Valores seguidos por letras distintas na coluna diferem entre si $(\mathrm{P}>0,05)$.

Tabela 2. Valores médios obtidos relacionados à secreção ocular em coelhos dos grupos tratado (T) e controle $(\mathrm{C})$ após o procedimento cirúrgico

\begin{tabular}{lrrrrrrr}
\hline \multirow{2}{*}{ Grupo } & \multicolumn{7}{c}{ Dia de observação } \\
\cline { 2 - 8 } & 1 & 2 & 7 & 9 & 12 & 14 & 15 \\
\hline $\mathrm{T}$ & $1,00 \mathrm{a}$ & $1,14 \mathrm{a}$ & $1,36 \mathrm{a}$ & $1,50 \mathrm{a}$ & $1,64 \mathrm{a}$ & $1,86 \mathrm{a}$ & $1,93 \mathrm{a}$ \\
$\mathrm{C}$ & $1,64 \mathrm{~b}$ & $2,00 \mathrm{~b}$ & $2,00 \mathrm{~b}$ & $2,00 \mathrm{~b}$ & $2,00 \mathrm{~b}$ & $2,00 \mathrm{a}$ & $2,00 \mathrm{a}$
\end{tabular}

Valores seguidos por letras distintas na coluna diferem entre si $(\mathrm{P}>0,05)$.

Tabela 3. Valores médios obtidos relacionados à congestão dos vasos conjuntivais em coelhos dos grupos tratado (T) e controle (C) após o procedimento cirúrgico

\begin{tabular}{lccccccccccc}
\hline \multirow{2}{*}{ Grupo } & \multicolumn{10}{c}{ Dia de observação } \\
\cline { 2 - 12 } & 1 & 2 & 4 & 7 & 8 & 12 & 14 & 15 & 16 & 17 & 19 \\
\hline $\mathrm{T}$ & $1,00 \mathrm{a}$ & $1,14 \mathrm{a}$ & $1,36 \mathrm{a}$ & $1,36 \mathrm{a}$ & $1,50 \mathrm{a}$ & $1,50 \mathrm{a}$ & $1,58 \mathrm{a}$ & $1,79 \mathrm{a}$ & $1,86 \mathrm{a}$ & $1,93 \mathrm{a}$ & $1,93 \mathrm{a}$ \\
$\mathrm{C}$ & $1,29 \mathrm{~b}$ & $1,50 \mathrm{~b}$ & $2,00 \mathrm{~b}$ & $2,00 \mathrm{~b}$ & $2,00 \mathrm{~b}$ & $2,00 \mathrm{~b}$ & $2,00 \mathrm{~b}$ & $2,00 \mathrm{~b}$ & $2,00 \mathrm{a}$ & $2,00 \mathrm{a}$ & $2,00 \mathrm{a}$ \\
\hline
\end{tabular}

Valores seguidos por letras distintas na coluna diferem entre si $(\mathrm{P}>0,05)$.

Somente os animais do grupo tratado apresentaram prurido, que persistiu por até sete dias durante o período pós-operatório, quando foi realizada a remoção da sutura (Tab. 4). Este resultado sugere que o fio de sutura atuou como um corpo estranho causando desconforto.

Até o quarto dia após a cirurgia, nenhum animal apresentou neovascularização corneana. Entre o quinto e $\mathrm{o} 30^{\circ}$ dia, a neovascularização foi significativa nos animais do grupo tratado. A partir daí não houve diferença entre os grupos (Tab. 5). Estes resultados diferem dos de Hao et al. (2000), que demonstraram a ação antiangiogênica da membrana amniótica por meio da expressão de um potente antiangiogênico químico, em todas as células epiteliais e em $20 \%$ das células mesenquimais do âmnio. Além disso, esses autores afirmaram que as propriedades antiinflamatórias da membrana amniótica diminuem o estímulo à angiogênese e, conseqüentemente, a neovascularização corneana. A neovascularização nos animais do grupo tratado pode ser explicada pela presença do fio de sutura, pois, após a sua remoção, houve involução dos vasos neoformados, e, como descrito por Slatter e Hakanson (1998), essa involução não se deu por completo, e os vasos puderam ainda ser vistos através de magnificação e iluminação.

Tabela 4. Valores médios obtidos relacionados ao prurido em coelhos dos grupos tratado (T) e controle (C) após o procedimento cirúrgico

\begin{tabular}{lccc} 
& Grupo & \multicolumn{3}{c}{ Dia de observação } \\
\cline { 2 - 4 } & 1 & 2 & 7 \\
\hline $\mathrm{T}$ & $1,00 \mathrm{a}$ & $1,00 \mathrm{a}$ & $1,00 \mathrm{a}$ \\
$\mathrm{C}$ & $2,00 \mathrm{~b}$ & $2,00 \mathrm{~b}$ & $2,00 \mathrm{~b}$ \\
\hline
\end{tabular}

Valores seguidos por letras distintas na coluna diferem entre si $(\mathrm{P}>0,05)$. 
Membrana amniótica canina...

Tabela 5. Valores médios obtidos relacionados à neovascularização em coelhos dos grupos tratado $(\mathrm{T}) \mathrm{e}$ controle (C) após o procedimento cirúrgico

\begin{tabular}{lccccccc}
\hline \multirow{2}{*}{ Grupo } & \multicolumn{7}{c}{ Dia de observação } \\
\cline { 2 - 8 } & 4 & 5 & 7 & 15 & 30 & 60 & 180 \\
\hline $\mathrm{T}$ & $1,93 \mathrm{a}$ & $1,50 \mathrm{a}$ & $1,29 \mathrm{a}$ & $1,43 \mathrm{a}$ & $1,57 \mathrm{a}$ & $1,86 \mathrm{a}$ & $1,96 \mathrm{a}$ \\
$\mathrm{C}$ & $2,00 \mathrm{a}$ & $2,00 \mathrm{~b}$ & $2,00 \mathrm{~b}$ & $2,00 \mathrm{~b}$ & $2,00 \mathrm{~b}$ & $2,00 \mathrm{a}$ & $2,00 \mathrm{a}$ \\
\hline
\end{tabular}

Valores seguidos por letras distintas na coluna diferem entre si $(\mathrm{P}>0,05)$.

Não houve diferença entre os grupos quanto ao resultado do teste de fluoresceína nos primeiros oito dias após a cirurgia. Do nono ao $23^{\circ}$ dia, os animais do grupo tratado apresentaram resultados positivos ao teste com maior significância que os animais do grupo-controle, e a partir desse dia não houve diferença entre os grupos (Tab. 6). Esperava-se que os animais do grupo tratado apresentassem epitelização em menor espaço de tempo se a membrana tivesse sido posicionada como implante, servindo como substrato para a migração celular, como descrito por Dua et al. (2004), ou se os grupos fossem constituídos por animais com ceratopatia autoimune ou com algum tipo de deficiência no processo de reparação corneana normal. Assim, os animais do grupo tratado apresentariam resultados mais satisfatórios do que os do grupo-controle.

Os animais utilizados apresentavam córneas com capacidade de regeneração perfeita e a membrana foi utilizada como bandagem. Dessa forma, esperava-se que os dois grupos tivessem tempo de reparação corneana semelhantes, já que a epitelização ocorre sob a membrana (Dua et al., 2004), mas o grupo tratado apresentou retardo na reparação. Este fato poderia ser explicado pela incorporação da membrana amniótica ao epitélio corneano, mesmo com a membrana sendo utilizada somente como bandagem. Ainda assim, seriam necessários estudos histológicos adicionais para um diagnóstico mais preciso.

Tabela 6. Valores médios obtidos relacionados ao teste de fluoresceína em coelhos dos grupos tratado (T) e controle (C) após o procedimento cirúrgico

\begin{tabular}{lccccccccc}
\hline \multirow{2}{*}{ Grupo } & 7 & 8 & 9 & 11 & 13 & 15 & 23 & 24 & 26 \\
\cline { 2 - 9 } & $1,29 \mathrm{a}$ & $1,58 \mathrm{a}$ & $1,58 \mathrm{a}$ & $1,57 \mathrm{a}$ & $1,64 \mathrm{a}$ & $1,64 \mathrm{a}$ & $1,78 \mathrm{a}$ & $1,86 \mathrm{a}$ & $1,93 \mathrm{a}$ \\
$\mathrm{T}$ & $1,43 \mathrm{a}$ & $1,64 \mathrm{a}$ & $1,93 \mathrm{~b}$ & $1,93 \mathrm{~b}$ & $2,00 \mathrm{~b}$ & $2,00 \mathrm{~b}$ & $2,00 \mathrm{~b}$ & $2,00 \mathrm{a}$ & $2,00 \mathrm{a}$ \\
\hline
\end{tabular}

Valores seguidos por letras distintas na coluna diferem entre si $(\mathrm{P}>0,05)$.

Houve início de queda da membrana no sétimo dia após a cirurgia, sendo necessária a remoção da sutura e da porção da membrana que não estivesse aderida à córnea.

Até o $18^{\circ}$ dia, a opacidade corneana foi mais intensa nos animais do grupo tratado, e a partir daí não houve diferença no grau de opacidade entre os grupos estudados, sendo que esta variável esteve presente em todos os animais durante o período em que foram observados (Tab. 7). Este resultado pode ser devido à presença de neovascularização corneana nos coelhos do grupo tratado, a qual permitiu a deposição de tecido de granulação e a formação de cicatriz, que foi mais densa e mais opaca que nos coelhos do grupo-controle. Nos animais do grupo-controle a reparação corneana se deu de forma avascular (Slatter, 1992; Slatter e Hakanson, 1998).

Tabela 7. Valores médios obtidos relacionados à opacidade corneana em coelhos dos grupos tratado $(\mathrm{T}) \mathrm{e}$ controle $(\mathrm{C})$ após o procedimento cirúrgico

\begin{tabular}{lcccccccc}
\hline \multirow{2}{*}{ Grupo } & \multicolumn{7}{c}{ Dia de observação } \\
\cline { 2 - 9 }$y$ & 2 & 7 & 10 & 18 & 19 & 30 & 60 & 180 \\
\hline $\mathrm{T}$ & $1,83 \mathrm{a}$ & $2,60 \mathrm{a}$ & $2,75 \mathrm{a}$ & $3,00 \mathrm{a}$ & $2,83 \mathrm{a}$ & $2,50 \mathrm{a}$ & $2,00 \mathrm{a}$ & $2,00 \mathrm{a}$ \\
$\mathrm{C}$ & $2,00 \mathrm{~b}$ & $1,40 \mathrm{~b}$ & $1,62 \mathrm{~b}$ & $2,50 \mathrm{~b}$ & $2,67 \mathrm{a}$ & $2,50 \mathrm{a}$ & $2,50 \mathrm{a}$ & $2,50 \mathrm{a}$
\end{tabular}

Letras diferentes na mesma coluna indicam diferença ao nível de 5\% de significância. 


\section{CONCLUSÕES}

De acordo com os resultados deste trabalho, a membrana amniótica canina utilizada como bandagem suturada à córnea de coelhos não demonstrou ser um método de tratamento eficaz em úlceras superficiais de córnea. Neste caso, não se indica esse método de tratamento.

\section{AGRADECIMENTOS}

Agradecemos à Ophthalmos Fórmulas Oficinais Ltda, à Petrovich Instrumentos Cirúrgicos e ao Dr. Paulo Eustáquio Jorge Daguer, médico oftalmologista, pelo apoio dado a este trabalho.

\section{REFERÊNCIAS BIBLIOGRÁFICAS}

AZUARA-BLANCO, A.; PILLAI, C.T.; DUA, H.S. Amniotic membrane transplantation for ocular surface reconstruction. Br. J. Ophthalmol., v.83, p.399-402, 1999.

BARROS P.S.M.; GARCIA J.A.; LAUS, J.L. et al. The use of xenologous amniotic membrane to repair canine corneal perforation created by penetrating keratectomy. Vet. Ophthalmol., v.1, p.119-123, 1998.

BARROS P.S.M.; SAFATLE, A.M.V.; GODOY, C.A. et al. Amniotic membrane transplantation for the reconstruction of the ocular surface in three cases. Vet. Ophthalmol., v.8, p.189-192, 2005.

CREMONINI, D.N.; RANZANI, J.J.T.; MARQUES, M.E.A. et al. Transplante de membrana amniótica canina criopreservada para cicatrização de córnea com deficiência de células límbicas em coelhos. Arq. Bras. Med. Vet. Zootec., v.59, p.1462-1467, 2007.

DUA, H.S.; GOMES, J.A.P.; KING, A.J. et al. The amniotic membrane in ophthalmology. Surv. Ophthalmol., v.49, p.51-77, 2004.
GARCIA, J.A.; BARROS, P.S.M.; LAUS, J.L. et al. Implante de peritônio homólogo conservado após ceratectomia lamelar em cães. Braz. J. Vet. Res. Anim. Sci., v.33, p.290-294, 1996.

HAO, Y.; MA, D.H.; HWANG, D.G. Identification of antiangiogenic and antiinflamatory proteins in human amniotic membrane. Cornea, v.19, p.348-352, 2000.

KERN, T.J. Ulcerative keratitis. Vet. Clin. North Am.: Small Anim. Pract., v.20, p.643-666, 1990.

PORTNOY, S.L.; INSLER, M.S.; KAUFMAN, H.E. Surgical management of corneal ulceration and perfuration. Surv. Ophthalmol., v.34, p.4758, 1989.

SAMPAIO, R.L.; RANZANI, J.J.T.; RODRIGUES JÚNIOR, V. et al. Aspectos clínicos e imunológicos da ceratoplastia com membrana amniótica xenógena fresca e conservada em glicerina. Estudo experimental em coelhos. Arq. Bras. Med. Vet. Zootec., v.58, p.1077-1085, 2006.

SLATTER, D. (Ed). Fundamentos de oftalmologia veterinaria. 2.ed. Buenos Aires: Inter-Médica Editorial, 1992. 739p.

SLATTER, D.; HAKANSON, N. Córnea e esclerótica. In: SLATTER, D. (Ed). Manual de cirurgia de pequenos animais. São Paulo: Manole, 1998. p.1436-1461.

TRELFORD, J.D.; TRELFORD-SAUDER, M. The amnion in surgery, past and present. Am. J. Obst. Ginecol., v.134, p.833-845, 1979.

WHITLEY, R.D. Canine cornea. In: GELATT, K.N. (Ed). Veterinary ophthalmology. 2.ed. Philadelphia: Lea e Febiger, 1991. p.357-356.

WOO, H-M.; KIM, M.S.; KWEON, O-K. et al. Effects of amniotic membrane on epithelial wound healing and stromal remodelling after excimer laser keratectomy in rabbit cornea. $B r . J$. Ophthalmol., v.85, p.345-349, 2001. 